\title{
Oak stave oxygen permeation: a new tool to make barrels with different wine oxygenation potential
}

\author{
Ignacio Nevares ${ }^{1}$ and Maria del Alamo-Sanza*2 \\ ${ }^{I}$ Dept. of Agroforestry Engineering, UVaMOX-University of Valladolid \\ ${ }^{2}$ Dept. of Analytical Chemistry, UVaMOX-University of Valladolid \\ *Author to whom correspondence should be addressed: E-mail delalamo@qa.uva.es
}

\begin{abstract}
The aim of this study was to classify rough staves according to their permeability to oxygen by measuring their transmission rate in order to assess the capacity to build barrels with high and low oxygen transmission rates (OTRs). The ability to assess the OTR would be important for better understanding and controlling the aging process of wine in barrels. To accomplish this, we built a device that measures the OTR of rough staves under the same conditions as those in a full barrel, in which the stave is in contact with a liquid solution on one face and with a diffusing gas on the opposite face. A total of 69 rough staves were classified to yield a high-OTR group, with a mean 2.6 times higher than the mean of the low-OTR group. A high-OTR and low-OTR barrel were constructed, and we confirmed that the stave OTR decreased between 3-and 4.5-fold in the barrels and that the high-OTR barrel allowed the entry of twice the concentration of oxygen compared to the low-OTR barrel. These results confirmed the capacity to classify rough staves and build barrels with different OTRs.
\end{abstract}

Keywords. Oxygen transmission rate, oak stave, oxygen permeation, barrel

\section{Introduction}

The supply of oxygen to aging wine in an oak-wood barrel has been previously studied ${ }^{I-}$ 2 , and the oxygen concentration that wine received during its aging in new French oak barrels was classified to be between 15 and $45 \mathrm{mg} /$ L.year. This supply varied according to the geographical origin of the oak. The need to age wine in barrels that provide small known oxygen amounts requires those in the cooperage industry to search for a parameter that allows the classification of wood based on this characteristic.

Typically, the choice of wood used to build barrels is made based on the grain, a parameter defined by Feuillat in 1992 according to the anatomic features of the wood ${ }^{3}$. Subsequently, in 1995, Vivas ${ }^{4}$ established a grain classification for French wood used in cooperage. According to this classification, very tight-grain wood had an annual growth less than $1 \mathrm{~mm}$, tight-grain 1-2 mm, medium-grain 2-4 mm, wide-grain 4-5 $\mathrm{mm}$ and very wide grain more than $5 \mathrm{~mm}$. This is the criterion typically used in cooperage, and the study established that wood with a finer grain is less porous than wood with coarser grain ${ }^{5}$. However, this hypothesis has been questioned by several authors, who suggest that wood porosity, and therefore its permeability to oxygen, is a very complex property. They propose that wood porosity is defined not only by the proportion of spring/summer wood in the annual growth but also by other anatomical features of the wood, such as the 
abundance of tyloses filling the vessels or the orientation of the medullary rays ${ }^{6-8}$. Therefore, it is too simple to establish a direct correlation between the wood grain and it porosity $^{8}$, and it is essential to find an evaluation system for the oxygen permeability of wood.

Outside of the oenology field, several authors have attempted to measure the oxygen permeability of wood. Many of these studies were conditioned by the existence of a pressure gradient on both sides of the wood, considered as a porous material in an anisotropic medium. Its properties vary according to the anatomical direction and hence comprise several structural factors that determine its porosity ${ }^{9}$. According to $\mathrm{Siau}^{10}$, liquids and gases can be transported through wood as a mass fluid under a pressure gradient as well as by diffusion caused by a concentration gradient. Gas flow controlled by a pressure difference is explained by Darcy's law, which greatly differs from the diffusion of a flow of low molecular mass under the influence of a concentration gradient, which is governed by Fick's first law. Although permeability has been defined by the magnitude of a flow through wood in this case, diffusion is produced along with flow processes, with both processes defining the transmission rate of a gas through a solid.

The measurement of gas permeability in membranes is made in both the steady and nonsteady states by one of three methods: the absorption of gases in the membrane, the permeation through the membrane in a sealed container or the permeation through the membrane in a gas stream. This last method has been used in reports of the American Society for Testing and Materials (ASTM) $)^{11-14}$ and by the International Organization for Standardization-ISO ${ }^{15-16}$ for the evaluation of the oxygen transmission rate (OTR) of a membrane located between two chambers: one filled with pure oxygen or air and the other without oxygen (nitrogen). The membrane is exposed to a gas flow, with a known oxygen concentration, passing through. The pressure or the volume of oxygen that enters the second chamber is measured through time, and the OTR is determined by the change in volume or pressure measured in that chamber. This procedure was followed by Vivas and his team ${ }^{17}$ in the only study published in the oenological field assessing the measurement of the OTR of oak wood used to build barrels. The limitations of the measurement equipment and those of the gas-wood-gas approach prevented these authors from determining the OTR in oak wood with the same thickness and similar conditions as those found when the wood is part of a barrel containing wine. This work places special importance on the role of moisture content (MC) in the loss of OTR in different wood samples. Other studies have measured oxygen permeability in completely flooded wood in a liquid-wood-liquid setting ${ }^{18}$. In such studies, it was evident that there is oxygen permeation in saturated wood, and the importance of the difference between early-wood and late-wood density was highlighted as well as the direction of the diffusion. Likewise, Sorz and Hietz ${ }^{19}$ highlight the importance of the $\mathrm{MC}$ in oxygen permeation by diffusion in different staves and in different directions. In a previous study ${ }^{20}$, the relation between oxygen entry through the wood and the increase in its moisture content was demonstrated. For this, the visualization of oxygen diffusion was performed through a French oak stave during moistening in conditions similar to those in a barrel. It was confirmed that the oxygen transmission rate decreases as MC increases with the liquid-wood contact time 
and that after 40 days, there is still oxygen permeation. This process of progressive moistening of the wood is also reflected in the OTR descending kinetic in new barrels, and this process results in a reduction of up to $40 \%$ two and a half months after being filled ${ }^{7}$.

The aim of this work was to develop a routine method for the classification of rough staves according to their OTR in working conditions similar to those in a barrel, considering the variation in the diffusion coefficient that wood undergoes during aging.

\section{Materials and Methods}

This study is organized into three phases. The first stage validates the device built for measuring the wood's OTR through the evaluation of the device's airtightness (OTRzero) and the measurement of a material acting as an oxygen barrier with known permeability. In the second phase, rough staves were classified according to their oxygen transmission rates, and from this classification, staves were made from the high- and low-OTR rough stave groups in order to build two barrels. In the third phase, barrels were built and tested to assess the total OTR of the barrel. Different routes for oxygen entry were also analyzed, hence differentiating between the OTR of the staves after their coopering process and the OTR due to oxygen entry through the joint of the different barrel wood pieces (usually known as gaps).

\section{Measurement device}

A device was developed for the quick measurement of the OTR of porous materials in contact with gas or liquids (Figure 1), including wood for oenology applications ${ }^{21}$. The device's dimensions were designed to maintain the same liquid volume: wood surface relation as in a Bordeaux $225 \mathrm{~L}$ barrel. Additionally, the hydrostatic pressure of the liquid in contact with the stave was established to be similar to the pressure of a stave at a barrel's half height thanks to the glass tube at the top of the device (Figure 1) so the column of liquid was similar to that in a barrel. The study of the diffusion of a gas through a membrane in order to assess the membrane's permeability to such gas and the gas' diffusivity in said membrane is performed using a classic assay following Crank's diffusion equations ${ }^{22}$. This method, Time Lag Permeation Technique, allows the effective determination of the OTR of different materials in a steady state, under specific circumstances $^{23}$, and in the case of wood, which is considered a porous solid ${ }^{19}$. The method is based on continuous monitoring of the amount of a penetrant diffusing through a solid membrane into a device chamber. ${ }^{24}$ The amount of gas recovered in the device chamber as a result of permeation through the membrane is plotted as a function of time. The steady state permeation of gases through a material with thickness $d(\mathrm{~m})$ is calculated using the following simple equation:

$$
J=P \cdot \frac{\Delta p_{O 2}}{d}
$$

where $J\left(\mathrm{~m}^{3}\right)$ is the volumetric flow of gas transported per unit of time (s) through a surface area $\left(\mathrm{m}^{2}\right)$, which, according to Eq. (1), is proportional to the constant partial pressure difference $\Delta p_{O 2}(\mathrm{~Pa})$ of oxygen between both sides of the solid membrane. The 
proportionality constant $P$ is called the permeability coefficient $\left(\mathrm{m}^{3} \cdot \mathrm{m} / \mathrm{m}^{2} \cdot \mathrm{s} \cdot \mathrm{Pa}\right)$. The method relies on the measure of the increase in oxygen partial pressure $\left(p_{2}\right)$ over time in an initially oxygen-depleted chamber. Of note, even upon reaching steady state permeation, the partial pressure $p_{2}$ of the permeated gas, oxygen, remains negligibly small compared to the partial pressure of the gas at the other side of the membrane, the atmospheric air $\left(p_{2}<<<p_{1}\right)$. A steady state is reached when the increase in $p_{2}$ with time is linear, indicating a constant oxygen entry through the membrane.

OTRzero. The device chamber was tested six times to ensure air tightness before the experiments were conducted by fixing a metal piece to the device in place of the membrane. The device's chamber was filled with $\mathrm{N}_{2}$, and the dissolved oxygen (DO) entry was monitored for $24 \mathrm{~h}$. Then, the OTRzero was established. Once the device tightness was confirmed and prior to each experiment, the accuracy of the oxygen sensor in the liquid chamber under the measurement conditions was verified with the device's chamber full of nitrogen.

Membrane with known permeability. To assess the device's capacity, the oxygen permeability was assessed for a membrane with a known permeability when used as a barrier for oxygen. Repeated measurements were performed using a membrane composed of three layers, polyethylene/polyethylene terephthalate metallized/ polyethylene (PE/PETmet/PE) with 50/12/50- $\mu \mathrm{m}$ thicknesses and oxygen permeability $\leq 1 \mathrm{cc} / \mathrm{m}^{2} \cdot 24 \mathrm{~h}$ tested by Smurfit Kappa (Spain) according to ASTM F $1927-0723^{\circ} \mathrm{C}$ relative humidity $75 \% .^{13}$

\section{Wood measurements}

The evaluation of rough staves requires the emulation of the conditions of a stave in a full barrel. Therefore, the device was used in a liquid-stave-air configuration. The same relation between the wood surface and liquid volume was maintained, and the system was given the capacity to control the necessary head space and its pressure according to the operation of a barrel. ${ }^{25-26}$

When a barrel is filled, the wood starts a moistening process, and the $\mathrm{MC}$ in the stave is not in a steady state. The variation of the $\mathrm{MC}$ in the wood of a $27 \mathrm{~mm}$ thick stave maintains a transition state for 82 days, which is the time necessary for the $\mathrm{MC}$ in the exterior part of the stave to increase after it contacts the liquid in the interior face. ${ }^{27}$ This fact is reflected in the OTR decrease in barrels, which reach an almost-steady point at two and a half months ${ }^{7}$. For this non-steady state, the equation proposed by $\mathrm{Crank}^{22}$ allows the use of the "Time Lag Permeation Technique", as long as two initial conditions are met by the study. The first condition demands that the membrane be at zero concentration of the gas to be measured, and the second is that the face through which the diffusing substance emerges is effectively maintained at zero concentration. If both conditions are met, the steady state is reached after a specific time (lag). This is the time at which the system reaches the steady state or a constant flow state and can be used to determine the diffusion coefficient of the permeated gas for the material ${ }^{28}$ and the OTR. Therefore, to measure a 
constant OTR, it would be necessary to moisten the wood for 82 days, which is when it reaches the steady state. This length of time would not allow the establishment of a routine method for the measurement of the OTR in wood. Moreover, in the first two and a half months of aging, the barrel doses close to $40 \%$ of all the oxygen that will be incorporated in the barrel contents in a year ${ }^{7}$. Therefore, if the wood was to be tested after the moisture stabilization period, the OTR obtained would not consider almost half of the total annual oxygen input. Bearing this in mind, we decided to condition the rough staves prior to the assay.

Wood conditioning. In this study, the wood was kept in contact with liquid for a week, which was considered to be the necessary moistening time for its conditioning. Additionally, to accelerate the equilibration transition process of $\mathrm{pO}_{2}$ inside the wood and reach a steady state, the device's chamber was completely depleted of oxygen before every assay for at least two hours to gradually remove any gas from the inner to the outer side of the oak wood sample. With this procedure, desorption phenomenon interference, a process described by other authors in porous materials, was avoided ${ }^{29-30}$. Moreover, we were able to reach the partial pressure gradient of the oxygen inside the wood earlier, similar to that produced in the barrel aging conditions, as reported previously ${ }^{20}$. We decided to work under these conditions in order to develop a quick routine method, without the requirements of the time lag permeation technique; this method demands great technical complexity and high stabilization times to achieve a stabilized MC and a $\mathrm{pO}_{2}$ equal to zero on the inside of a porous material such as wood, with a thickness of a barrel stave $(27 \mathrm{~mm})$.

Wood measuring conditions. Once depleted of gas, the device's chamber was filled with a previously oxygen-free model wine propelled with nitrogen $(99.9992 \%$ Carburos Metálicos, Barcelona, Spain). Model wine was used instead of wine because the oxygenconsuming compounds of the wine would not allow the measurement of oxygen delivered to the wine. Wood compounds capable of consuming oxygen are considered to closely reproduce conditions similar to those in an operating barrel; otherwise, the amount of oxygen reaching the wine through wood could be overestimated. To reproduce the conditions under which increased oxygen transmission occurs in a barrel ${ }^{26,31}$, the pressure inside the chamber filled with liquid was adjusted to $-100 \mathrm{hPa}$, using a syringe in the system's head space, controlled with a pressure transducer (Transmitter S-10, Wika, Lawrenceville, GA, USA) in the upper part of the tube (Figure 1).

All the assays were performed in a climate-controlled barrel room, and the holder temperature was kept constant $\left(15 \pm 0.01^{\circ} \mathrm{C}\right)$ using a Julabo FP40-ME thermostatic bath (Seelbach, Germany).

\section{OTR measurement}

The oxygen permeation of wood pieces is performed measuring the increase in the oxygen partial pressure with time $(\mathrm{hPa} /$ day), which allows the determination of the OTR using the law of ideal gases ${ }^{32-33}$. 


$$
O T R=\frac{\Delta n \cdot V_{m}}{\Delta t}=\frac{\Delta p_{O 2} \cdot V}{R \cdot T} \cdot \frac{V_{m}}{\Delta t}=\frac{\Delta p_{O 2} \cdot V}{\Delta t \cdot P_{a t m}}
$$

where $n$ is the amount of a substance in moles, $V_{m}$ is the molar volume of oxygen, $T$ is the absolute temperature in ${ }^{o} K, \frac{\Delta p_{\mathrm{O} 2}}{\Delta t}$ is the slope in the linear part of $\mathrm{hPa} / \mathrm{day}, V$ is the device's chamber volume, and $P_{\text {atm }}$ is the atmospheric pressure in $\mathrm{hPa}$ during the assay Henry's law was applied to evaluate the oxygen concentration $(\mathrm{mg} / \mathrm{L})$, and the Bunsen absorption coefficient $\left(\mathrm{cm}^{3}\left(\mathrm{O}_{2}\right) / \mathrm{cm}^{3}\right)$ of oxygen in hydro-alcoholic mixtures ${ }^{34}$ was used to avoid sub-estimation measurements when oxygen solubility is water was used ${ }^{35}$.

\section{Rough staves}

For the second part of this study, we worked with Radoux Cooperage personnel (Jonzac, France), who selected 69 French oak rough staves (Quercus petraea) of the Allier forest with a greater length $(120 \mathrm{~cm})$ than is typical $(90 \mathrm{~cm})$. Wood pieces (pieces A and B) were extracted from both ends of the rough stave. A total of 138 pieces were sent to our Center for analysis using the same methodology previously described. The remaining parts of each rough stave, now with the typical dimensions, were stored in the cooperage for the production of staves and further construction of the barrels according to the classification delivered by our Center. The tested wood pieces had effective dimensions of a 40-mm diameter and a thickness of approximately $27 \mathrm{~mm}$. The effective surface area for oxygen transmission was $12.57 \times 10^{-4} \mathrm{~m}^{2}$. All of the samples were stored under environmental conditions of $15^{\circ} \mathrm{C}$ and $75 \%$ relative humidity, maintaining the $\mathrm{MC}$ of the pieces between 14 and $15 \%$.

\section{Measurement in barrels}

Two barrels of $225 \mathrm{~L}$ were built using 25 staves selected from the high- or low-OTR groups. The OTRs of the barrels were measured following the protocol described previously $^{7}$ and barrel total OTR (wood+gaps) was obtained. After these tests, the oxygen transmission rate of the barrel wood was also evaluated (wood OTR). For this, all joints and gaps were sealed with epoxy, and before the tests, all barrels were conditioned to ensure that the wood had recovered its initial moisture (14\% MC).

All tests were performed following the protocol of the cumulative measurement of dissolved oxygen inside the barrel. Barrels were filled with model wine that was previously de-oxygenated according to a previous report ${ }^{7}$. When the measurements showed the constant absence of dissolved oxygen, the barrels were topped with this solution and were sealed with an expandable modified silicon bung, which ensured air tightness. This bung had a feedthrough for both optical fibers of the submergible oxygen probes introduced in each barrel.

The OTR in barrels is typically expressed in $\mathrm{mg} / \mathrm{L} . \mathrm{year}^{17}{ }^{36}$. To express the OTR in $\mathrm{mL} / \mathrm{L}$.year, we used the parameters of 225 liters and $2.01 \mathrm{~m}^{2}$ of internal wood surface. Bearing in mind the importance of the time of the experiments in the annual OTR measurement, this work expresses the measurement as $\mu \mathrm{g} / \mathrm{L} \cdot \mathrm{day}$.

During all tests, the barrels were stored in a climate-controlled cellar, where the room temperature was $15^{\circ} \mathrm{C}$ and humidity was $75 \%$, to maintain the typical air physical properties in a real cellar situation, regarding diffusion and permeability. 


\section{Oxygen partial pressure measurement}

The measurement of dissolved oxygen in the device ${ }^{13}$ was performed using an Oxytrace device (PreSens GmbH, Germany) equipped with a PSt6 oxygen sensor (measurement range $0-41.4 \mathrm{hPa}$, detection limit $0.002 \% \mathrm{O}_{2}$ ). This sensor was placed inside the device in direct contact with the fluid of the chamber that, according to the test, was nitrogen or synthetic wine. Luminescent measurements were performed using an optical fiber through a transparent surface where the sensor was attached. For the measurement of the dissolved oxygen levels inside the barrels, we used two submergible oxygen probes in each barrel. The probes were equipped with a PSt6 sensor with a four-channel OXY-4 trace transmitter (PreSens $\mathrm{GmbH}$, Germany) connected to a computer. To determine the representative mean value of the dissolved oxygen concentration in the fluid of each barrel, the arithmetic mean of every barrel was calculated ${ }^{7}$.

Calibration of the oxygen systems in the tonometer ${ }^{37}$ was performed using a conventional two-point calibration in the model wine saturated with nitrogen (cal 0 ) and a second value in the range between 5 and $10 \%$ air saturation. A calibration gas mixture with $2.001 \%$ ( $\pm 0.5 \%$ rel) pure oxygen gas and nitrogen $(9.55 \%$ air-sat) was used as a second calibration standard (Carburos Metálicos, Spain). Both gases were pumped into the tonometer for 10 minutes at a constant $15^{\circ} \mathrm{C}$ until stable conditions were achieved. All measurements performed for $\mathrm{pO}_{2}$ were corrected to compensate for the interferences introduced by ethanol, according to the model developed in previous studies ${ }^{38}$.

Statistical analysis. Data were collected using Microsoft Excel$^{\circledR} 2013$ software (Redmond, WA, USA).

\section{Results and discussion}

Zeros. Initially, six measurements of the oxygen entry rate were performed in the device when it has been hermetically closed with a stainless steel piece. These measurements, called zeros, allowed us to assess the hermeticity of the device, and the mean result was subtracted from the measurements performed. The results are shown in Table 1 and indicate that the device has a mean zero of $0.1714 \times 10^{-9} \mathrm{~cm}^{3} / \mathrm{m}^{2}$.day. This value was low enough to ensure the air-tightness of the device.

Measurement repeatability. Six assays were performed in the same membrane sample previously described to know the repeatabilty. The measurements were performed following the "Time Lag Permeation Technique" 33 to check the accurate performance of the newly designed system, indicated by the zero value and the correct measurement of the reference film.

The results obtained correspond to the manufacturer's indications (less than 1 $\mathrm{cm}^{3} / \mathrm{m}^{2}$.day) because the OTR measured in the material varies from $0.689 \mathrm{~cm}^{3} / \mathrm{m}^{2}$.day to $0.760 \mathrm{~cm}^{3} / \mathrm{m}^{2}$.day. This represents an average permeability (P) of $0.730 \mathrm{~cm}^{3} / \mathrm{m}^{2}$. day and 
a repeatability of $\mathrm{r}=0.023 \mathrm{~cm}^{3} / \mathrm{m}^{2}$.day. Therefore, the device meets all the necessary requirements to evaluate the OTR of materials (Table 1).

Oak wood OTR. The construction of barrels with different oxygenation levels demands the determination of the OTR of the rough staves. For this, the OTR of 138 wood pieces was evaluated following the protocol of dissolved oxygen cumulative measurement in the device, as described in Materials and Methods ${ }^{13}$. Figure 2 shows the increase in oxygen concentration in the device chamber according to the measurement time in the evaluation of some pieces.

Table 2 shows the results obtained expressed as $\mu \mathrm{g}$ of oxygen transferred by the wood to each liter of wine during a day ( $\mu \mathrm{g} / \mathrm{L}$.day), accumulating the mean of the data obtained from the pieces extracted from each rough stave (piece A, top end; piece B, lower end). These results indicate that in some rough staves, the difference between the pieces of both ends is small, as was the case for rough stave 1 (piece $A=196.41 \mu \mathrm{g} / \mathrm{L}$.day and piece $\mathrm{B}=198.31 \mu \mathrm{g} / \mathrm{L}$.day) and rough stave 29 (piece $\mathrm{A}=113.20 \mu \mathrm{g} / \mathrm{L}$ day and piece $\mathrm{B}=117.11$ $\mu \mathrm{g} / \mathrm{L}$.day). However, in other cases, the difference is quite large, such as in the case of rough stave 31 (piece $\mathrm{A}=209.86 \mu \mathrm{g} / \mathrm{L}$.day and piece $\mathrm{B}=413.97 \mu \mathrm{g} / \mathrm{L}$.day) and rough stave 49 (piece $\mathrm{A}=150.71 \mu \mathrm{g} / \mathrm{L}$.day and piece $\mathrm{B}=266.23 \mu \mathrm{g} / \mathrm{L}$.day). This result reflects the wood's natural structural variability throughout the stave, which also affects its physical properties and hence most likely alters its capacity for transmitting oxygen.

The result of the average OTR measured from both ends was considered representative of all of the rough staves and allowed the establishment of the stave classification in two groups. This classification excluded 19 rough staves with values between 180 and $211 \mu \mathrm{g}$ $\mathrm{L}^{-1}$ day $^{-1}$, did not clearly belong to any of the two groups. The group of rough staves with a low OTR included staves with an average OTR between 48 and $177 \mu \mathrm{g} / \mathrm{L}$.day, which represents the group mean OTR of $140 \mu \mathrm{g} / \mathrm{L}$.day. In contrast, the group of rough staves with a high OTR included staves with an average OTR between 213 and $379 \mu \mathrm{g} / \mathrm{L}$.day, for a total group mean of $265 \mu \mathrm{g} / \mathrm{L}$.day (Table 2).

Once a barrel is built, the potential oxygen contribution from the wood must also include the contribution from the gaps. This outcome depends on the assemblage process of each cooperage and on the wood type. Moreover, it is important to bear in mind that the OTR of a rough stave will be modified in the bending and toasting processes performed in the cooperage because they modify the shape and maybe also slightly the structure of the wood and therefore most likely affect its OTR.

OTR-grain relation. To assess the relation between the OTR and the real grain of rough staves, the number of rings present in $5 \mathrm{~cm}$ of wood in the transversal section of the rough staves was measured following the medullary rays, yielding the mean width of a growth ring. The results found for the 138 analyzed pieces are shown in Table 2. The classification was also performed according to Vivas $^{4}$, as described previously.

The correlation analysis between the oxygen transmission rate and the measured grain indicates that this relation is very low (correlation $=-0.0216, p=0.8014$ ). This same result 
was obtained when the OTR was analyzed with the grain classified according to Vivas (correlation $=-0.1172, p=0.1712$ ).

Barrel construction. Finally, the barrels were built using 25 staves of each group for each barrel, discarding the staves with an intermediate OTR between the two groups. The barrels were manufactured in the Radoux Cooperage (Jonzac, France), using the regular process with a medium toast.

The results obtained from the assessment of the oxygen entry into the barrels is shown in Figure 3, which displays the increase in dissolved oxygen content in both barrels during 11 days of testing. As expected, the global entrance of oxygen was higher in the barrels that were constructed with rough staves classified with a high OTR than in the barrels constructed with rough staves classified with a low OTR. This experiment was used to assess the aim that was initially proposed. Specifically, it has been found that the highOTR barrel would supply the aging wine with a total of $116 \mathrm{mg}$ of oxygen ( $225 \mathrm{~L}$ x 519.02 $\mu \mathrm{g} / \mathrm{L})$ in 11 days on average, while the low-OTR barrel would supply only $105 \mathrm{mg}$ of oxygen $(225 \mathrm{~L} \times 471 \mu \mathrm{g} / \mathrm{L})$ in 11 days. These global results indicate that the barrel with a high OTR would transfer only $10 \%$ more oxygen to the wine than the low-OTR barrel, a result that is not satisfactory in regards to our aim. To perform a comparison of the OTR that is dependent only on the classified staves, it is necessary to analyze in detail the different ways oxygen enters the barrel.

To evaluate the potential of the classification system proposed for the rough staves, the rate of oxygen entry due exclusively to the oxygen transmission process of the wood from the staves of the barrels was evaluated. Figure 3 also shows the oxygen that exclusively enters through the wood, measured in the epoxy-sealed barrels. This procedure allowed us to directly calculate the OTR corresponding to the wood (Table 3 ). It also permitted us to calculate the oxygen that enters through the gaps as the difference of OTR between the unsealed and the sealed barrel. It was observed that in the case of the barrel with a high OTR, the contribution was $83.8 \mathrm{mg}(225 \mathrm{~L}$ x $372.27 \mu \mathrm{g} / \mathrm{L})$ of the $116.8 \mathrm{mg}$ of total oxygen in 11 days. This result indicates that $72 \%$ of the oxygen that the aging wine would receive in the high-OTR barrel would enter through the wood, while the $33 \mathrm{mg}$ of oxygen ( $225 \mathrm{~L}$ $x 146.75 \mu \mathrm{g} / \mathrm{L}$ ) that would enter the barrels through the stave gaps would comprise $28 \%$ of the total.

In the case of the barrel with a low OTR, it was found that the $48 \mathrm{mg}$ of oxygen $(225 \mathrm{~L} \mathrm{x}$ $213.31 \mu \mathrm{g} / \mathrm{L}$ ) that entered the barrel through the wood in 11 days represents $46 \%$ of the total oxygen that enters to the barrel, with 54\% entering through the gaps. According to the results obtained, the treatment and manufacturing process of the staves from the rough staves classified as having high and low permeability considerably affected the properties of the wood, as expected. Definitively, the high-OTR staves allowed 1.74 times more oxygen to enter the barrel $(372 \mathrm{mg} / \mathrm{L})$ than the low-OTR staves $(213 \mathrm{mg} / \mathrm{L})$. 
To compare the previously obtained results from the evaluation of the built barrel staves (evaluated for 11 days) with those obtained for rough staves (evaluated for one day using the proposed method), an extrapolation was performed to know the rough stave OTR of 11 days. For this, we included the results of our group's previous studies that were published recently ${ }^{7}$, in which it was demonstrated that the entrance of oxygen to the barrels does not follow a linear variation with time but a potential evolution, such as $\mathrm{y}=$ $a t^{0.7789}$ in the case of French barrels ${ }^{39}$. Therefore, from the contribution of the first 24 hours and considering this model as an approximation of the behavior of French oak barrels, we calculated the constant $a$ for the high- and low-OTR barrels, extrapolating it to 11 days. We found that the high-OTR rough staves would allow $1682.92 \mu \mathrm{g} / \mathrm{L}$ oxygen in and that the low-OTR rough staves would allow $642.23 \mu \mathrm{g} / \mathrm{L}$ oxygen in. These data indicate that the high-OTR rough staves would permit 2.6 times as much oxygen to enter the barrel as the low-OTR rough staves in 11 days.

Analyzing the effect that the bending and toasting processes have on the OTR of rough staves, we found that wood's oxygen permeation decreases between 3 and 4.5 times after these processes. Specifically, after the 11-day evaluation, we found that in the case of high-OTR wood, these changed from dosing $1.68 \mathrm{mg} / \mathrm{L}$ in rough staves to $0.37 \mathrm{mg} / \mathrm{L}$ in toasted staves, which represents a 4.5 -fold decrease in the OTR. In the case of low-OTR wood, they went from $0.64 \mathrm{mg} / \mathrm{L}$ in rough staves to $0.21 \mathrm{mg} / \mathrm{L}$ in toasted staves. Therefore, wood loses up to 3 times its oxygen transfer rate during the toasting process. This result agrees with previously reported studies ${ }^{5,39}$, which demonstrate the loss of the gas permeability of oak wood after the bending and toasting processes.

From the detailed analysis of the oxygen entrance through the gaps, the results show that the oxygen that enters into the wine in this way greatly varies from one barrel to another. In this case, we found that $56.7 \mathrm{mg}(225 \mathrm{~L} \times 251.87 \mu \mathrm{g} / \mathrm{L})$ of oxygen entered through the gaps of the low-OTR barrels, almost 1.7 times the $33 \mathrm{mg}$ of oxygen entering the highOTR barrel (225 L x $146.75 \mu \mathrm{g} / \mathrm{L})$. Bearing in mind that the cooperage is the same (and therefore, so is the manufacturing system of both barrels), it is possible to conclude that the assembly system make an important contribution for the variability between barrels.

In conclusion, this study proposes a device and a procedure for the routine measurement of the OTR of oak wood. It is important to highlight that the device has the capacity to reproduce working conditions that are similar to those of the barrel, which allows its use in the classification of rough staves for the manufacturing of barrels. In this way, after the classification of rough staves, two barrels with different oxygen transfer rates were built. Specifically, it was demonstrated that the high-OTR barrel allows almost twice as much oxygen to be transferred throughout the oak wood into the wine as the low-OTR barrel. The results show that the classification of rough stave wood has indeed allowed the construction of barrels with high and low oxygen permeability, accomplishing our aim. The importance of the assembly of staves in the global OTR during barrel construction has been confirmed, a result that requires a deeper study on the factors determining the 
Nevares, I.; del Alamo-Sanza, M., Oak stave oxygen permeation: a new tool to make barrels with different wine oxygenation potentials. Journal of A gricultural and Food Chemistry, 2015, 63, 1268-1275.

OTR in this process. Moreover, it was confirmed that the toasting and bending processes are important in the oxygen permeability decrease in oak wood used for barrel making.

\section{Funding}

This work was financed by Ministerio de Ciencia e Innovacion (AGL2011-26931) and by Junta de Castilla y León (VA-086A11-2) from Spain.

\section{Acknowledgements}

The authors acknowledge Carlos González Muñoz for the data acquisition. The authors express great appreciation to Tonelería Radoux (Jonzac, Francia) for their collaboration.

\section{References}

1. Ribereau-Gayon, J. Contribution à l'étude des oxydations et réductions dans les vins. Ph.D. Thesis, Université de Bordeaux, 1933.

2. Vivas, N.; Glories, Y., Modélisation et calcul du bilan des apports d'oxygène au cours de l'élevage des vins rouges. II. Les apports liés au passage d'oxygène au travers de la barrique. Progrès Agric. Vit. 1997, 114, 315-316.

3. Feuillat, F.; Huber, F.; Keller, Knowledge on 'grain' used for the classification of stave oak wood, Quercus robur L.; Quercus petraea Liebl. Rev. Fran. D'Oenol. 1992, 32, 65-69.

4. Vivas, N., Sur la notion de grain en tonnellerie. J. Sci. Tech. Tonn 1995, 1, 17-32.

5. Boeglin, N.; Kuzara, S.; Duchanois, G.; Masson, D., Étude du chêne de tonnellerie: Perméabilité et cintrage. Rev. Fran. D'Oenol. 1993, 144, 35-40.

6. Pracomtal, G.; Mirabel, M., Teissier du Cros, R.; Monteau, A., Types of oak grain, wine elevage in barrel. Pract Winery Vineyard 2014, July, 64-69.

7. del Alamo-Sanza, M.; Nevares, I., Recent advances in the evaluation of the oxygen transfer rate in oak barrels. J. Agric. Food Chem. 2014, 62, 8892-8899.

8. Feuillat, F.; Keller, R., Variability of oak wood (Quercus robur L., Quercus petraea Liebl.) Anatomy relating to cask properties. Am. J. Enol. Vitic. 1997, 48, 502-508.

9. Hansmann, C.; Gindl, W.; Wimmer, R.; A., T., Permeability of wood - a review Wood Res. 2012, 47, 1-16.

10. Siau, J. F., Transport processes in wood. Springer-Verlag: Berlin ; New York, 1984; $\mathrm{p}$ ix, $245 \mathrm{p}$

11. ASTM D1434 - 82(2009)e1 Standard Test Method for Determining Gas Permeability Characteristics of Plastic Film and Sheeting. In ASTM International: West Conshohocken, PA, 2009; Vol. 15.10.

12. ASTM D3985 - 05(2010)e1. Standard Test Method for Oxygen Gas Transmission Rate Through Plastic Film and Sheeting Using a Coulometric Sensor. In ASTM International: West Conshohocken, PA, 2010; Vol. 15.10.

13. ASTM F1927 - 14. Standard Test Method for Determination of Oxygen Gas Transmission Rate, Permeability and Permeance at Controlled Relative Humidity 
Through Barrier Materials Using a Coulometric Detector. In ASTM International: West Conshohocken, PA, 2014; Vol. 15.10.

14. ASTM F1307 - 14. Standard Test Method for Oxygen Transmission Rate Through Dry Packages Using a Coulometric Sensor. In ASTM International: West Conshohocken, PA, 2014; Vol. 15.10.

15. ISO, 15105-1. Plastics -- Film and sheeting -- Determination of gas-transmission rate -- Part 1: Differential-pressure methods. In International Organization for Standardization: Geneva, Switzerland, 2007; Vol. TC 61 Plastics.

16. ISO, 15105-2. Plastics -- Film and sheeting -- Determination of gas-transmission rate -- Part 2: Equal-pressure method. In International Organization for Standardization: Geneva, Switzerland, 2003; Vol. TC 61 Plastics.

17. Vivas, N.; Debèda, H.; Ménil, N.; Vivas de Gaulejac, N.; Nonier, M., Mise en évidence du passage de l'oxygène au travers des douelles constituant les barriques par l'utilisation d'un dispositif original de mesure de la porosité du bois. Premiers résultats. Sci. Aliment. 2003, 23, 655-678.

18. Huang, H. I.; Sarkanen, K. V.; Johanson, L. N., Diffusion of dissolved oxygen in liquid-saturated Douglas fir sapwood. Wood Sci. Tech 1977, 11, 225-236.

19. Sorz, J.; Hietz, P., Gas diffusion through wood: implications for oxygen supply. Trees Struc. Func. 2006, 20, 34-41.

20. Nevares, I.; Crespo, R.; Gonzalez, C.; del Alamo-Sanza, M., Imaging of oxygen transmission in the oak wood of wine barrels using optical sensors and a colour camera. Aust. J. Grape Wine Res. 2014, 20,353-360.

21. Del Alamo, M.; Nevares, I. PCT/ES2012/070084 Device for measuring the permeability and diffusivity of gases in porous materials and method for measuring said parameters using the device. 2012.

22. Crank, J., The Mathematics of Diffusion, . 1986.

23. Rutherford, S. W., Review of time lag permeation technique as a method for characterisation of porous media and membranes. Adsorption 1997, 3, 283-312.

24. Piringer, O. G.; Baner, A. L., Permeation of gases, water vapor and volatile organic compounds. In Plastic packaging materials for food: barrier function, mass transport, quality assurance, and legislation New York, 2000.

25. Nevares, I.; del Alamo-Sanza, M., Oxygène et barriques Actualisation des connaissances quantité et voies de pénétration de l'oxygène dans la barrique. Rev OEnol 2014, 153, 1-4.

26. Moutounet, M.; Mazauric, J. P.; Saint-Pierre, B.; Hanocq, J. F., Gaseous exchange in wines stored in barrel. J. Sci. Tech. Tonn 1998, 4, 131-145.

27. Feuillat, F. Study on interrelations between wood, wine and atmosphere using a model wooden cask. Relations with the anatomy of oak wood (*Quercus robur* L., *Quercus petraea* Liebl.). Ph.D. Thesis, Ecole Nationale du Génie Rural des Eaux et des Forêts, Nancy; France, 1996.

28. Saikumar, V.; Jaccodine, R. J., Time lag and permeation in multilayer polymer coatings. Components, Hybrids, and Manufacturing Technology, IEEE Transactions 1993, 16, 517-522. 
29. Skouroumounis, G.; Waters, E., Oxygen ingress into bottled wine. Pract. Win. Vin. 2008, July-August, 1-4.

30. Lopes, P.; Silva, M. A.; Pons, A.; Tominaga, T.; Lavigne, V. r.; Saucier, C. d.; Darriet, P.; Teissedre, P.-L.; Dubourdieu, D., Impact of oxygen dissolved at bottling and transmitted through closures on the composition and sensory properties of a sauvignon blanc wine during bottle storage. J. Agric. Food Chem. 2009, 57, 1026110270.

31. Moutounet, M.; Mazauric, J. P.; Saint-Pierre, B.; Micaleff, J.; Sarris, J., Causes et conséquences de microdéformations des barriques au cours de l'élevage des vins. Rev. D'Oenol. 1994, 74, 34-39.

32. Diéval, J. B.; Vidal, S.; Aagaard, O., Measurement of the oxygen transmission rate of co-extruded wine bottle closures using a luminescence-based technique. Pack. Tech. Sci. 2011, 7, 375-385.

33. Timineri, D.; John, G. T.; Müller, K.; Huber, C., oxygen permeation measurement with chemical optical sensors. In Meetingpack2013, Valencia, 2013.

34. Mejane, J. V.; Debailleul, M.; Lecerf, J., Étude sur la solubilité de l'oxygène dans l'alcool. Ind. Aliment. Agri. 1973, 90, 719-727.

35. Nevares, I.; del Alamo Sanza, M.; Waters, E.; Day, M. In La medida del oxígeno disuelto en vino y mostos, ¿Concentración o presión parcial?: estado actual del conocimiento, XIII Congreso Latinoamericano de Viticultura y Enología, Santiago de Chile, 21-23 November 2011, 2011; Santiago de Chile, 2011.

36. Peterson, R., Formation of reduced pressure in barrels during wine aging. Am.J.Enol.Vitic 1976, 27, 80-81.

37. Proctor, K. G.; Bohlen, H. G., Tonometer for calibration and evaluation of oxygen microelectrodes. J Appl Physiol 1979, 46, 1016-1018.

38. del Alamo-Sanza, M.; Pando, V.; Nevares, I., Investigation and correction of the interference of ethanol, sugar and phenols on dissolved oxygen measurement in wine. Anal. Chim. Acta 2014, 809, 162-173.

39. Hugi, E.; Wuersch, M.; Risi, W:; Wakili, K., Correlation between charring rate and oxygen permeability for 12 different wood species. J. Wood Sci. 2007, 53, 71-75. 
Table 1. Results of the tests performed with the device for the evaluation of the zero oxygen transfer rate $\left(\mathrm{OTR}_{z e r o} \mathrm{X} 10^{9}\right)$ and the permeability $(\mathrm{P})$ of a known membrane (PE/PETmet/PE) expressed in $\mathrm{cm}^{3} \mathrm{~m}^{-2} \mathrm{day}^{-1}$.

\begin{tabular}{ccccccccc}
\hline & Test 1 & Test 2 & Test 3 & Test 4 & Test 5 & Test 6 & mean & SD \\
OTR $_{\text {zero X 10 }}$ & 1.778 & 1.575 & 1.755 & 1.733 & 1.969 & 1.477 & 1.714 & 0.171 \\
$\mathrm{P}$ & 0.7227 & 0.7601 & 0.7310 & 0.7393 & 0.7393 & 0.6895 & 0.7303 & 0.0235 \\
\hline
\end{tabular}

Table 2. Mean values of the OTR in rough staves. 1 Grain value measuring the number of rings in $5 \mathrm{~cm}$ of a stave. 2 Grain according to Vivas's classification $(1,<1 \mathrm{~mm} ; 2$, between 1 and $2 \mathrm{~mm} ; 3$, between 2 and $4 \mathrm{~mm}$, between 4 and $5 \mathrm{~mm}$; and 5 , > $5 \mathrm{~mm}$ ).

\begin{tabular}{|c|c|c|c|c|c|c|c|c|c|}
\hline $\begin{array}{l}\text { Rough } \\
\text { stave }\end{array}$ & piece & OTR $\mu \mathrm{g} / \mathrm{L}$.day & $\begin{array}{c}\text { Measured } \\
\text { grain }^{1}\end{array}$ & Grain $^{2}$ & $\begin{array}{l}\text { Rough } \\
\text { stave }\end{array}$ & piece & OTR $\mu \mathrm{g} / \mathrm{L}$.day & $\begin{array}{l}\text { Measured } \\
\text { grain }^{1}\end{array}$ & Grain $^{2}$ \\
\hline \multirow[t]{2}{*}{1} & $\mathrm{~A}$ & 196.41 & 2.70 & 3 & 36 & A & 188.25 & 1.56 & 3 \\
\hline & B & 198.31 & 1.92 & 2 & & B & 563.75 & 1.82 & 3 \\
\hline \multirow[t]{2}{*}{2} & $\mathrm{~A}$ & 215.94 & 2.27 & 3 & 37 & A & 136.53 & 1.20 & 2 \\
\hline & B & 441.82 & 2.33 & 3 & & B & 122.42 & 1.92 & 3 \\
\hline \multirow[t]{2}{*}{3} & $\mathrm{~A}$ & 163.03 & 4.76 & 4 & 38 & A & 109.48 & 1.56 & 3 \\
\hline & B & 275.80 & 5.26 & 5 & & B & 428.25 & 0.98 & 2 \\
\hline \multirow[t]{2}{*}{4} & $\mathrm{~A}$ & 214.73 & 4.55 & 4 & 39 & A & 161.85 & 1.18 & 2 \\
\hline & B & 245.67 & 3.23 & 3 & & B & 454.33 & 1.79 & 3 \\
\hline \multirow[t]{2}{*}{5} & $\mathrm{~A}$ & 178.48 & 3.13 & 3 & 40 & $\mathrm{~A}$ & 123.84 & 1.72 & 3 \\
\hline & $\mathrm{B}$ & 279.60 & 1.45 & 2 & & B & 181.92 & 1.52 & 3 \\
\hline \multirow[t]{2}{*}{6} & $\mathrm{~A}$ & 178.07 & 2.08 & 3 & 41 & $\mathrm{~A}$ & 121.91 & 1.54 & 3 \\
\hline & B & 236.40 & 2.94 & 3 & & B & 191.66 & 1.59 & 3 \\
\hline \multirow[t]{2}{*}{7} & A & 198.04 & 2.22 & 3 & 42 & A & 195.71 & 1.09 & 2 \\
\hline & B & 161.78 & 2.50 & 3 & & B & 174.96 & 1.16 & 2 \\
\hline \multirow[t]{2}{*}{8} & $\mathrm{~A}$ & 72.38 & 2.27 & 3 & 43 & A & 125.07 & 1.14 & 2 \\
\hline & $\mathrm{B}$ & 98.75 & 2.17 & 3 & & B & 203.98 & 0.96 & 2 \\
\hline \multirow[t]{2}{*}{9} & $\mathrm{~A}$ & 118.67 & 2.27 & 3 & 44 & A & 102.71 & 1.52 & 3 \\
\hline & B & 337.61 & 1.47 & 2 & & B & 137.02 & 1.82 & 3 \\
\hline \multirow[t]{2}{*}{10} & $\mathrm{~A}$ & 142.56 & 2.78 & 3 & 45 & A & 109.00 & 1.56 & 3 \\
\hline & B & 283.72 & 1.67 & 3 & & B & 150.89 & 1.61 & 3 \\
\hline \multirow[t]{2}{*}{11} & A & 149.92 & 3.57 & 3 & 46 & A & 215.55 & 1.67 & 3 \\
\hline & B & 192.65 & 2.78 & 3 & & B & 139.50 & 1.56 & 3 \\
\hline \multirow[t]{2}{*}{12} & $\mathrm{~A}$ & 103.66 & 1.59 & 3 & 47 & A & 129.36 & 1.28 & 2 \\
\hline & B & 200.48 & 1.96 & 3 & & B & 179.86 & 1.52 & 3 \\
\hline \multirow[t]{2}{*}{13} & $\mathrm{~A}$ & 113.25 & 1.61 & 3 & 48 & A & 160.49 & 2.56 & 3 \\
\hline & B & 290.92 & 2.38 & 3 & & B & 243.07 & 3.03 & 3 \\
\hline \multirow[t]{2}{*}{14} & A & 168.39 & 2.22 & 3 & 49 & A & 150.71 & 1.37 & 2 \\
\hline & B & 354.34 & 2.04 & 3 & & B & 266.23 & 1.43 & 2 \\
\hline \multirow[t]{2}{*}{15} & $\mathrm{~A}$ & 153.49 & 1.96 & 3 & 50 & A & 142.21 & 1.69 & 3 \\
\hline & B & 176.61 & 2.00 & 3 & & B & 233.70 & 1.47 & 2 \\
\hline \multirow[t]{2}{*}{16} & A & 89.03 & 2.63 & 3 & 51 & A & 153.01 & 1.43 & 2 \\
\hline & B & 163.85 & 1.45 & 2 & & B & 165.70 & 1.82 & 3 \\
\hline \multirow[t]{2}{*}{17} & $\mathrm{~A}$ & 242.12 & 2.44 & 3 & 52 & A & 122.04 & 2.17 & 3 \\
\hline & B & 221.50 & 2.27 & 3 & & B & 86.86 & 2.50 & 3 \\
\hline 18 & $\mathrm{~A}$ & 161.03 & 1.79 & 3 & 53 & A & 208.47 & 2.17 & 3 \\
\hline
\end{tabular}


Nevares, I.; del Alamo-Sanza, M., Oak stave oxygen permeation: a new tool to make barrels with different wine oxygenation potentials. Journal of A gricultural and Food Chemistry, 2015, 63, 1268-1275.

\begin{tabular}{|c|c|c|c|c|c|c|c|c|c|}
\hline & B & 223.81 & 2.00 & 3 & & B & 346.65 & 1.92 & 3 \\
\hline \multirow[t]{2}{*}{19} & A & 146.38 & 1.85 & 3 & 54 & A & 80.38 & 1.75 & 3 \\
\hline & B & 276.62 & 2.13 & 3 & & B & 15.89 & 1.67 & 3 \\
\hline \multirow[t]{2}{*}{20} & A & 136.89 & 2.00 & 3 & 55 & A & 147.73 & 1.69 & 3 \\
\hline & B & 148.16 & 1.96 & 2 & & B & 250.25 & 2.17 & 3 \\
\hline \multirow[t]{2}{*}{21} & A & 197.89 & 2.17 & 3 & 56 & A & 178.02 & 2.86 & 3 \\
\hline & B & 130.60 & 2.00 & 3 & & B & 212.18 & 3.03 & 3 \\
\hline \multirow[t]{2}{*}{22} & A & 179.57 & 2.04 & 3 & 57 & A & 165.96 & 2.86 & 3 \\
\hline & B & 271.30 & 1.49 & 2 & & B & 232.27 & 2.86 & 3 \\
\hline \multirow[t]{2}{*}{23} & A & 153.81 & 1.89 & 3 & 58 & $\mathrm{~A}$ & 358.00 & 1.05 & 2 \\
\hline & B & 369.39 & 1.54 & 3 & & B & 215.54 & 2.22 & 3 \\
\hline \multirow[t]{2}{*}{24} & A & 161.41 & 2.08 & 3 & 59 & A & 218.81 & 1.89 & 3 \\
\hline & B & 494.33 & 2.08 & 3 & & B & 234.72 & 1.56 & 3 \\
\hline \multirow[t]{2}{*}{25} & A & 91.22 & 2.33 & 3 & 60 & $\mathrm{~A}$ & 203.60 & 2.38 & 3 \\
\hline & B & 149.18 & 2.13 & 3 & & B & 200.79 & 1.96 & 3 \\
\hline \multirow[t]{2}{*}{26} & A & 157.37 & 2.08 & 3 & 61 & $\mathrm{~A}$ & 436.37 & 1.39 & 2 \\
\hline & B & 241.05 & 2.22 & 3 & & B & 253.51 & 1.25 & 2 \\
\hline \multirow[t]{2}{*}{27} & A & 329.84 & 1.41 & 2 & 62 & A & 221.36 & 2.70 & 3 \\
\hline & B & 213.23 & 1.56 & 3 & & B & 214.81 & 2.63 & 3 \\
\hline \multirow[t]{2}{*}{28} & A & 120.36 & 2.70 & 3 & 63 & A & 233.76 & 2.50 & 3 \\
\hline & B & 200.39 & 2.00 & 2 & & B & 287.53 & 2.00 & 2 \\
\hline \multirow[t]{2}{*}{29} & A & 113.20 & 1.61 & 3 & 64 & A & 110.46 & 1.64 & 3 \\
\hline & B & 117.11 & 2.17 & 3 & & B & 110.06 & 1.67 & 3 \\
\hline \multirow[t]{2}{*}{30} & A & 199.57 & 1.89 & 3 & 65 & A & 206.98 & 1.92 & 3 \\
\hline & B & 288.45 & 1.52 & 3 & & B & 109.63 & 1.79 & 3 \\
\hline \multirow[t]{2}{*}{31} & A & 209.86 & 1.82 & 3 & 66 & A & 150.84 & 2.63 & 3 \\
\hline & B & 413.97 & 2.50 & 3 & & B & 188.71 & 1.64 & 3 \\
\hline \multirow[t]{2}{*}{32} & A & 141.81 & 2.17 & 3 & 67 & A & 198.59 & 2.50 & 3 \\
\hline & B & 415.43 & 2.33 & 3 & & B & 149.25 & 2.86 & 3 \\
\hline \multirow[t]{2}{*}{33} & $\mathrm{~A}$ & 164.88 & 1.89 & 3 & 68 & $\mathrm{~A}$ & 266.75 & 1.85 & 3 \\
\hline & B & 255.65 & 1.89 & 3 & & B & 140.68 & 1.56 & 3 \\
\hline \multirow[t]{2}{*}{34} & A & 294.23 & 1.64 & 3 & 69 & A & 262.53 & 3.45 & 3 \\
\hline & B & 310.97 & 1.61 & 3 & & B & 147.06 & 2.94 & 3 \\
\hline \multirow[t]{2}{*}{35} & $\mathrm{~A}$ & 181.41 & 2.04 & 3 & & & & & \\
\hline & B & 196.72 & 2.04 & 3 & & & & & \\
\hline
\end{tabular}

Table 3. Cumulative dissolved oxygen content in barrels with a high or low OTR, penetrated by different entry routes after 11 days.

\begin{tabular}{lccc} 
& \multicolumn{3}{c}{ Low OTR barrel } \\
\cline { 2 - 4 } Total & $\mu \mathrm{g} \mathrm{L}^{-1}$ & mg per barrel \\
Wood & 465.18 & 104.7 & $100 \%$ \\
Gaps & 213.31 & 48.0 & $46 \%$ \\
& 251.87 & 56.7 & $54 \%$ \\
& \multicolumn{3}{c}{ High OTR barrel } \\
Total & 519.02 & 116.8 & $100.00 \%$ \\
Wood & 372.27 & 83.8 & $72 \%$ \\
Gaps & 146.75 & 33.0 & $28 \%$ \\
\hline
\end{tabular}


Figure 1. Porous material OTR measuring device.

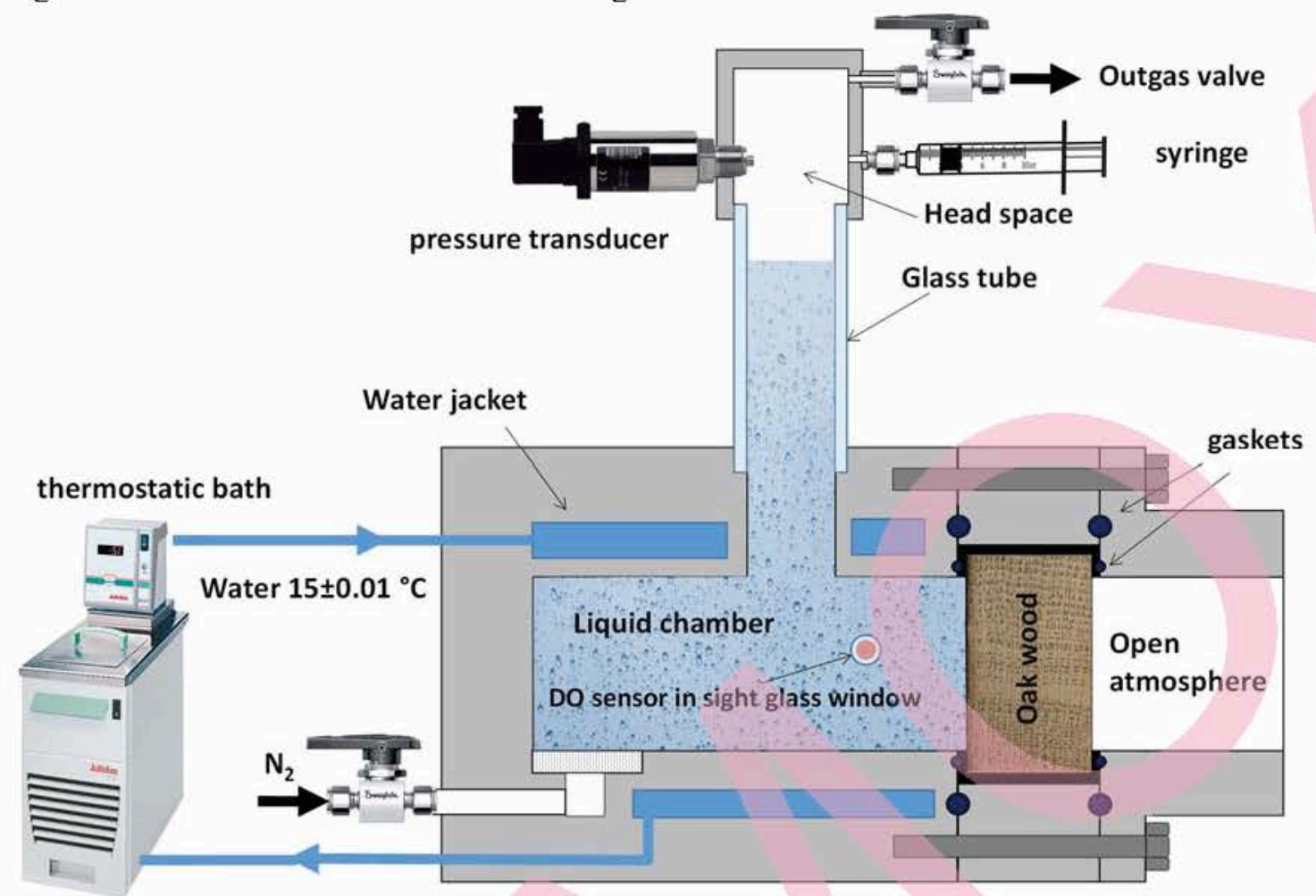

Figure 2. Comparative measurements of the evolution of the dissolved oxygen content $(\mathrm{hPa})$ of five different wood pieces.

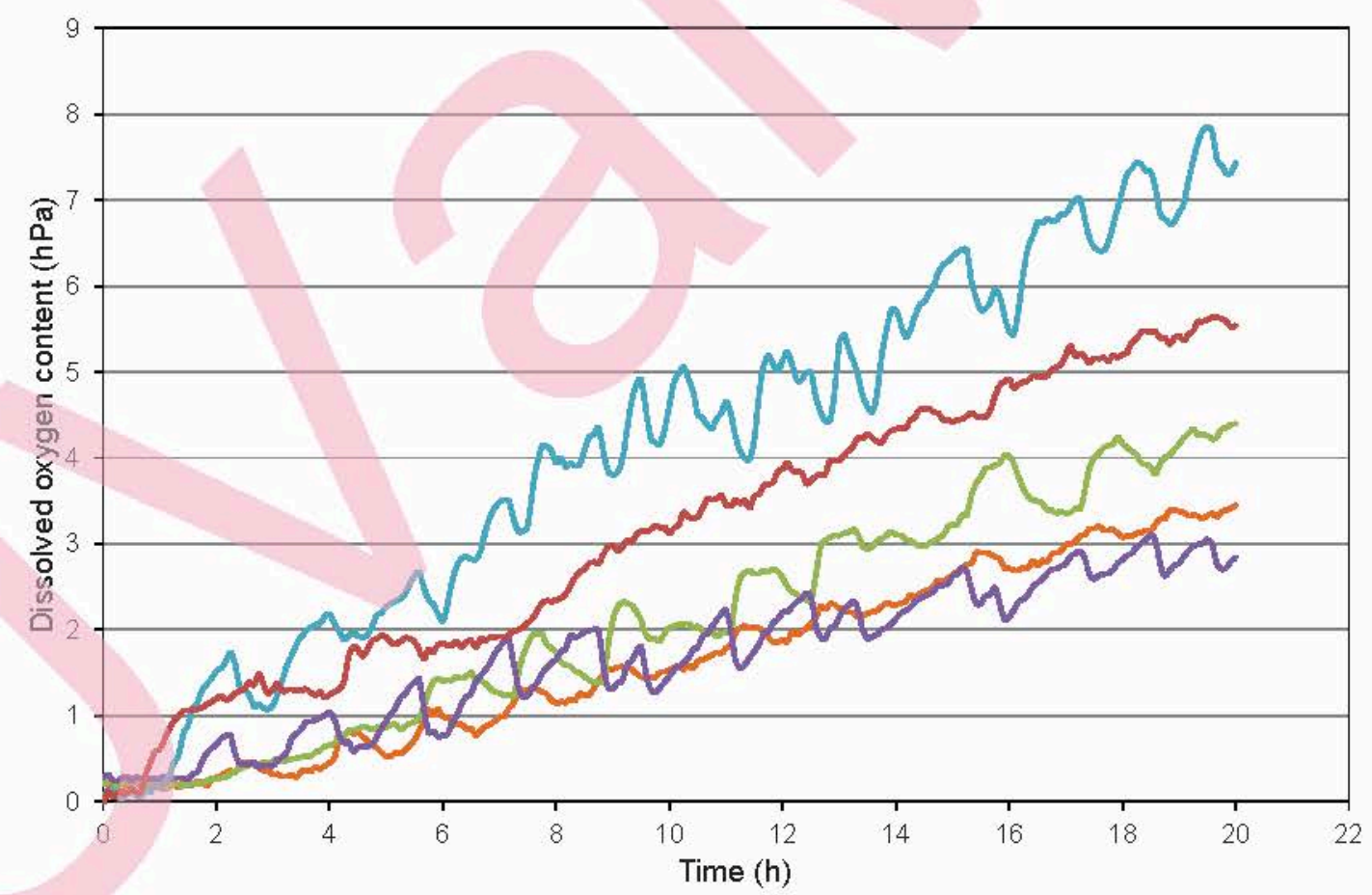


Nevares, I.; del Alamo-Sanza, M., Oak stave oxygen permeation: a new tool to make barrels with different wine oxygenation potentials. Journal of A gricultural and Food Chemistry, 2015, 63, 1268-1275.

Figure 3. Cumulative measurements of the dissolved oxygen content $(\mathrm{hPa})$ inside barrels with a high (HO in red) and low (LO in green) OTR, with sealed (---) and non-sealed gaps $(-)$.

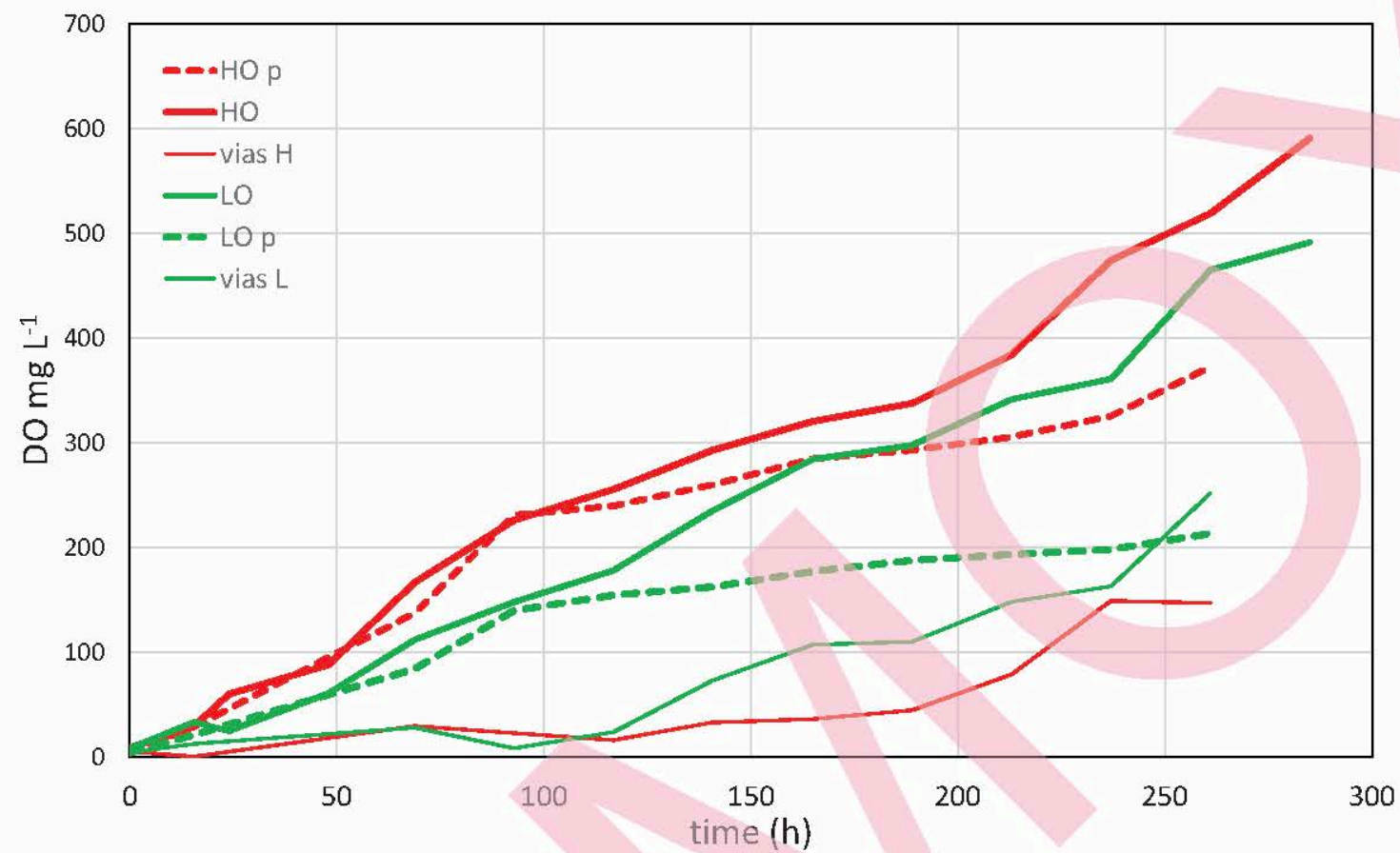

